\title{
Efficacy of Posaconazole Oral Suspension in Prevention and Treatment of Invasive Fungal Infections in Siriraj Hospital
}

Methee Chayakulkeeree, Thanunya Ngamsutham

Department of Medicine, Faculty of Medicine Siriraj Hospital, Mahidol University, Bangkok, Thailand

Correspondence: methee.cha@mahidol.ac.th

Bankground: A second-generation triazole, posaconazole, has been used for prophylaxis and treatment for fungal infections in high risk individuals. However, efficacy of posaconazole oral suspension has never been evaluated in Thai patients which have higher prevalence of invasive fungal diseases.

Objective: The objective of this study is to evaluate the efficacy of posaconazole oral suspension in prevention and treatment of invasive fungal diseases in patients at Siriraj Hospital.

Methods: We retrospectively reviewed medical records of patients admitted at Siriraj Hospital, who were prescribed posaconazole oral suspension for either prophylaxis or treatment, from January 2010 to December 2016. Clinical characteristics, breakthrough infections and treatment outcomes were analyzed.

Results:

There were 80 patients enrolled in this study. A total of 71 patients received posaconazole for prophylaxis and all of them had hematologic malignancies with neutropenia.

Among 9 patients who received posaconazole for treatment of invasive fungal diseases, 4 had diabetes mellitus and the other 4 had hematologic malignancies.

In those who received prophylaxis, breakthrough invasive fungal diseases were found in 13 patients (18.3\%) and invasive aspergillosis was the most common infection, diagnosed in 9 patients (69\%).

The median time to performed posaconazole therapeutic drug concentration (TDM) in those with and without breakthrough infections were 7 and 13 days, respectively $(p=0.029)$. Approximately $50 \%$ of patients with breakthrough fungal infections had suboptimal plasma posaconazole concentration ( $\leq 0.7 \mu \mathrm{g} / \mathrm{ml}$ ), whereas suboptimal concentration was found in only $29 \%$ in those without breakthrough infection $(p=0.169)$.

In treatment group, 8 patients (88.9\%) were cured. One patient died and she was the only one who had hematologic malignancy and did not perform therapeutic drug monitoring.

Table 1: Therapeutic drug monitoring (TDM) in patients receiving posaconazole prophylaxis $(\mathrm{N}=71)$

\begin{tabular}{|c|c|c|c|}
\hline & \begin{tabular}{|c} 
No \\
breakthrough IFI \\
$(\mathrm{N}=58)$
\end{tabular} & $\begin{array}{l}\text { breakthrough IFI } \\
\qquad(\mathrm{N}=13)\end{array}$ & $p$-value \\
\hline $\begin{array}{l}\text { Median time to first } \\
\text { posaconazole TDM } \\
\text { (days) }\end{array}$ & $7(3-28)$ & $13(4-40)$ & 0.029 \\
\hline $\begin{array}{l}\text { Posaconazole } \\
\text { concentration } \\
(\mu \mathrm{g} / \mathrm{mL})\end{array}$ & $\begin{array}{c}1.00 \\
(0.34-4.35)\end{array}$ & $\begin{array}{c}0.63 \\
(0.50-1.79)\end{array}$ & 0.084 \\
\hline $\begin{array}{l}\text { Patients with } \\
\text { plasma } \\
\text { posaconazole } \\
\text { concentration } \\
<0.7 \mu \mathrm{g} / \mathrm{mL}\end{array}$ & $15(29 \%)$ & $6(50 \%)$ & 0.169 \\
\hline
\end{tabular}

$\mathrm{IFI}=$ invasive fungal infection, $\mathrm{TDM}=$ therapeutic drug monitoring.

Multivariate study included parameters with $p<0.05$.

The results above were presented in median (range) or $\mathrm{N}(\%)$

\section{Discussion:}

Compared with previous studies, we found higher incidence of breakthrough invasive fungal diseases in patient received prophylactic posaconazole $(18.3 \%)$. This could be due to environmental factors, durg-drug interaction and/or sub-optimal posaconazole level.

Although no clear correlation has been shown between plasma posaconazole concentration and breakthrough IFI, plasma posaconazole concentration of $>0.7 \mu \mathrm{g} / \mathrm{mL}$ has been suggested as optimal concentration for fungal prophylaxis.

We demonstrated that the patients who had delayed TDM exhibited a significant higher rate of breakthrough IFI. The median time to performed posaconazole TDM in those with and without breakthrough infections were 13 and 7 days, respectively. The delay in posaconazole TDM may result in breakthrough fungal diseases in those receiving posaconazole prophylaxis.

Furthermore, posaconazole concentration below $0.7 \mathrm{ug} / \mathrm{ml}$ may be associated with development of breakthrough IFI. The findings is consistent with a previous study by Jang $\mathrm{SH}$ et al., who found that $6.5 \%$ (6 out of 92) of patients who had posaconazole concentration below $0.7 \mathrm{ug} / \mathrm{ml}$ had breakthough $\mathrm{IFI}$, whereas only $1.9 \%$ (3 out of 160 ) patients who had posaconazole concentration above $0.7 \mathrm{ug} / \mathrm{ml}$ had breakthough IFI. Also, the posaconazole concentration reached to steady state after 7 days. A study by Dolton, MJ, et al. also showed similar results.

If we perform posaconazole concentration at 7 days after receiving posaconazole prophylaxis, we could adjust dose of posaconazole earlier and may be able to decrease the rate of breakthrough IFI.

\section{Conclusion:}

Posaconazole oral suspension seem to be less efficacious in preventing IFD in Thais, partly may be due to higher incidence of invasive fungal diseases, lack or delayed therapeutic drug monitoring resulting in suboptimal plasma drug concentration. Posaconazole was effective in treatment of IFD.

\section{References:}

1. Jang SH, Colangelo PM, Gobburu JVS. Exposure-response of posaconazole used for prophylaxis against invasive fungal infections: evaluating the need to adjust doses based on drug concentrations in plasma. Clin Pharmacol Ther 2010; 88: 115-19.

2. Dolton MJ, Ray JE, Chen SC-A, Ng K, Pont L, McLachlan AJ. Multicenter Study of Posaconazole Therapeutic Drug Monitoring: Exposure-Response Relationship and Factors Affecting Concentration. Antimicrobial Agents and Chemotherapy. 2012;56(11):5503-10. 